\title{
What is the Rate of Revision Discectomies After Primary Discectomy on a National Scale?
}

\author{
Sohrab S. Virk MD, MBA, Ashish Diwan PhD, FRACS, FAOrthA, Frank M. Phillips MD, \\ Harvinder Sandhu MD, Safdar N. Khan MD
}

Received: 2 February 2017/Accepted: 1 August 2017/Published online: 28 August 2017

(C) The Association of Bone and Joint Surgeons (B) 2017

\begin{abstract}
Background Lumbar discectomy has been shown to be clinically beneficial in numerous studies for appropriately selected patients. Some patients, however, undergo revision discectomy, with previously reported estimates of revisions ranging from $5.1 \%$ to $7.9 \%$. No study to date has been able to precisely quantify the rate of revision surgery over numerous years on a national scale.

Questions/Purpose We performed a survival analysis for lumbar discectomy on a national scale using a lifetable analysis to answer the following questions: (1) What is the rate of revision discectomy on a national scale over 5 to 7 years for patients undergoing primary discectomy alone? (2) Are there differences in revision discectomy
\end{abstract}

Each author certifies that he or she has no commercial associations (eg, consultancies, stock ownership, equity interest, patent/licensing arrangements, etc) that might pose a conflict of interest in connection with the submitted article.

All ICMJE Conflict of Interest Forms for authors and Clinical Orthopaedics and Related Research ${ }^{\mathbb{R}}$ editors and board members are on file with the publication and can be viewed on request.

The Ohio State University waived approval for the human protocol for this investigation, and each author certifies that all investigations were conducted in conformity with ethical principles of research.

This work was done at The Ohio State University Wexner Medical Center, Columbus, OH, USA.

S. S. Virk, S. N. Khan

Department of Orthopaedics, The Ohio State University Wexner Medical Center, Columbus, OH, USA

A. Diwan

Department of Orthopaedic Surgery, St. George Hospital, The

University of New South Wales, Sydney, NSW, Australia

F. M. Phillips

Midwest Orthopaedics at Rush University, Chicago, IL, USA rates based on age of patient, region of the country, or the payer type?

Methods The Medicare 5\% National Sample Administrative Database (SAF5) and a large national database from Humana Inc (HORTHO) were used to catalog the number of patients undergoing a lumbar discectomy. Both of these databases have been cited in numerous peer-reviewed publications during the previous 5 years and routinely are audited by PearlDiver Inc. We identified patients using relevant ICD-9 codes and Current Procedural Terminology (CPT) codes, including ICD-9 72210 (lumbar disc displacement) for disc herniation. We used appropriate CPT codes to identify patients who had a lumbar discectomy. We analyzed patients undergoing additional surgery including those who had repeat discectomy (CPT-63042: laminotomy, reexploration single interspace, lumbar) and patients who had additional more-extensive decompressive procedures with or without fusion after their primary procedure. Revision surgery rates were calculated for patients 65 years and older and those younger than 65 years and for each database (Humana Inc and Medicare). Patients from the two databases also were analyzed based on four distinct geographic regions in the United States where their surgery occurred. There were a total of 7520 patients who underwent a lumbar discectomy for an intervertebral disc displacement with at least 5 years of followup in the

H. Sandhu

Hospital for Special Surgery, New York, NY, USA

S. N. Khan $(\square)$

Department of Orthopaedics, The Ohio State University Wexner

Medical Center, 725 Prior Hall, 410 West 10th Avenue,

Columbus, OH 43210, USA

e-mail: safdar.khan@osumc.edu 
HORTHO and SAF5 databases. We used cumulative incidence of revision surgery to estimate the survivorship of these patients.

Results In the HORTHO (2613 patients) and SAF5 (4907 patients) databases, 147 patients $(5.6 \%$; 95\% CI, $1.8 \%-$ $9.2 \%)$ and 305 patients $(6.2 \%$; 95\% CI, 3.5\%-8.9\%) had revision surgery at 7 years after the index discectomy respectively. Survival analysis showed survival rates greater than $93 \%(95 \%$ CI, 91\%-98\%) for all of the cohorts for a primary discectomy up to 7 years after the surgery. The survivorship was lower for patients younger than 65 years $(93 \%$ [95\% CI, 87\%-99\%, 1016 of 1091] versus $95 \%$ [95\% CI, 90\%-100\%, 1450 of 1522], p = 0.02). When nondiscectomy lumbar surgeries were included, the survivorship of patients younger than 65 years remained lower (83\% [95\% CI, 76\%-89\%, 902 of 1091] versus $87 \%$ [95\% CI, 82\%-92\%, 1324 of 1522], $\mathrm{p}=0.02)$. There was no difference in revision discectomy rates across geographic regions $(\mathrm{p}=0.41)$ at 7 years. Similarly, there was no difference in additional nondiscectomy lumbar surgery rates $(\mathrm{p}=0.68)$ across geographic regions at 7 years. There was no difference in survivorship rates between patients covered by Medicare (94\% [95\% CI, 91\%-97\%], 4602 of 4907) versus Humana Inc (94\% [95\% CI, 90\%-98\%], 2466 of 2613) ( $\mathrm{p}=0.31)$.

Conclusions Our study shows rates of cumulative survival after an index lumbar discectomy with revision discectomy as the endpoint. We hope these data allow physicians to offer accurate advice to patients regarding the risk of revision surgery for patients of all ages during 5 to 7 years after their index procedure to enhance shared decision making in spinal surgery. These data also will help public policymakers and accountable care organizations accurately allocate scarce resources to patients with symptomatic lumbar disc herniation.

Level of Evidence Level III, therapeutic study.

\section{Introduction}

Discectomy with and without laminectomy has been shown to be beneficial in numerous studies [10, 11, 16, 20, $22,24]$. Indications for the procedure include radiculopathy and progressive neurologic deficit in the presence of imaging confirming neural compression from a disc herniation. For patients who undergo this type of surgery, return to the operating room for a repeat discectomy may represent a failure of the original surgery to satisfactorily resolve a patient's symptoms [10], or alternatively, may indicate a new or recurrent herniation [10]. Gaston and Marshall [10] studied 993 patients after discectomy at a single institution and reported a rate of revision surgery of
$7.9 \%$ at 10 years followup, which is in the range reported by others (Table 1) $[2,3,6,9,10]$. The studies specifically deal with microdiscectomy procedures and therefore typically are less invasive than a larger laminectomy procedure.

National databases allow the opportunity to analyze a large group of patients to determine clinical and financial information regarding patients with a specific condition or who undergo a defined surgical procedure [17]. Studies using claims information from the Medicare database and private payer databases have been used in various clinical settings [13, 14, 21]. These databases are powerful tools to gain clinical and financial insights regarding medical care in a diverse patient population. Specifically, by using these databases we wanted to better define the rate of revision discectomies. Current studies suggest a revision discectomy rate between $5 \%$ to $7.9 \%$ and given that the estimated number of discectomies for Medicare patients in 2002 was approximately 89,320 based on Medicare estimated population, the number of revision discectomies would be estimated at between 4400 and 7056 [5, 23]. This not only represents a large range in terms of the number of procedures, but also the cost related to revision discectomies to the healthcare system.

We wanted to analyze revision rates for discectomy using two epidemiologic databases (Humana Inc and Medicare) to answer two questions: (1) What is the rate of revision discectomies on a national scale over 5 to 7 years for patients undergoing primary discectomy alone? (2) Is the survival rate for primary discectomy different for patients based on age of the patient ( 65 years old and older versus those younger than 65 years), region in which the primary discectomy takes place, or the payer type?

\section{Patients and Methods}

We queried the Humana orthopaedic private payer database (HORTHO) and the Medicare 5\% national sample administrative database (SAF5) to identify patients who

Table 1. Summary of published results on revision rates for microdiscectomy

\begin{tabular}{lllll}
\hline Study & $\begin{array}{l}\text { Year of } \\
\text { publication }\end{array}$ & $\begin{array}{l}\text { Followup } \\
\text { (years) }\end{array}$ & $\begin{array}{l}\text { Number of } \\
\text { patients }\end{array}$ & $\begin{array}{l}\text { Revision } \\
\text { rate }(\%)\end{array}$ \\
\hline $\begin{array}{l}\text { Findlay et al. } \\
\text { [9] }\end{array}$ & 1998 & 10 & 79 & 5.1 \\
$\begin{array}{l}\text { Gaston and } \\
\text { Marshall [10] }\end{array}$ & 2003 & 10 & 993 & 7.9 \\
\hline
\end{tabular}

Both of these studies included only patients undergoing a microdiscectomy procedure rather than a larger open procedure. 
had undergone an intervertebral disc excision. This search was performed using software from PearlDiver (PearlDiver Inc, Colorado Springs, CO, USA). This database is compliant with all regulations associated with the Health Insurance Portability and Accountability Act (HIPAA) as all patient identifiers were removed from clinical and financial information. Furthermore, since all patient information was deidentified and involved patients across the country, no institutional review board approval was required for this study. We used ICD-9 codes and Current Procedural Terminology (CPT) codes to identify patients who had undergone a lumbar discectomy (Table 2). The HORTHO database has patient information from 2007 to 2015 and the SAF5 database has patient information from 2005 to 2014. The SAF5 and HORTHO databases can be queried for regional variation. These set regions are based on four geographic regions in the United States. These predefined regions include the Northeast, West, Southeast, and Midwest. A patient is included in a certain region based on their surgical location. To allow for a reasonable followup, only patients who were enrolled in the SAF5 and HORTHO databases for at least 5 years after their index procedure were included in our analysis. We performed a separate analysis to determine the rate of dropout from the Medicare and Humana databases. We examined the differences regarding age, geographic region, comorbidities, and rate of revision surgery between those who had 5 years of followup data versus those who dropped out of the database before years after their index procedure. Comorbidities were measured based on the Charleston Comorbidity Index. Both of these databases have been audited for accuracy based on patient record audits, provider payment integrity audits, on-site audits, and desk audits as detailed on the PearlDiver Inc website [19].

Our query was performed by first selecting patients with an intervertebral disc herniation by searching for ICD-9 72210 (lumbar disc displacement). We then used CPT63030 (laminotomy with decompression of nerve roots and/or excision of herniated intervertebral disc) and CPT63056 (transpedicular approach with decompression of nerve roots through removal of herniated intervertebral disc) to select patients who had a lumbar discectomy. To ensure that these patients were only being treated with a primary lumbar discectomy at one level on the day of surgery, any patient with codes related to multiple-level disc herniations, spinal instrumentation, and arthrodesis were excluded if the code was billed on the same day or before the lumbar discectomy code. If, however, a fusion or multilevel decompression was coded for a patient after their initial decompressive surgery, then these patients

Table 2. CPT and ICD-9 codes used

\begin{tabular}{|c|c|c|}
\hline Code & Description & Included or excluded \\
\hline ICD-9 72210 & Lumbar disc displacement & Included \\
\hline СРT-63030 & $\begin{array}{l}\text { Laminotomy (hemilaminectomy) with } \\
\text { decompression of nerve root(s), including } \\
\text { partial facetectomy foraminotomy and/or } \\
\text { excision of herniated intervertebral disc; one } \\
\text { interspace lumbar (including open or } \\
\text { endoscopically assisted approach). }\end{array}$ & Included \\
\hline СРT-63056 & $\begin{array}{l}\text { Transpedicular approach with decompression } \\
\text { of spinal cord equina and/or nerve root(s) } \\
\text { (eg, herniated intervertebral disc) single } \\
\text { segment; lumbar (including transfacet or } \\
\text { lateral extraforaminal approach) (eg, far } \\
\text { lateral herniated intervertebral disc) }\end{array}$ & Included \\
\hline $\begin{array}{l}\text { CPT-22101, CPT-22102, CPT-22103, CPT- } \\
\text { 22110, CPT-22114, CPT-22116, CPT- } \\
\text { 22707, CPT-22208, CPT-22214, CPT- } \\
\text { 22224, CPT-22533, CPT-22534, CPT- } \\
\text { 22558, CPT-22586, CPT-22612, CPT- } \\
\text { 22630, CPT-22633, CPT-22800:CPT- } \\
\text { 22819, CPT-22840:CPT-22865 }\end{array}$ & $\begin{array}{l}\text { CPT-22630 - Arthrodesis, posterior interbody } \\
\text { technique, lumbar } \\
\text { CPT-22558 - Arthrodesis, anterior interbody } \\
\text { technique, lumbar } \\
\text { CPT-22842 - Posterior segmental } \\
\text { instrumentation, 3-6 vertebral segments }\end{array}$ & $\begin{array}{l}\text { Excluded if they were billed before or on the } \\
\text { same day as lumbar decompression surgery. } \\
\text { If a patient had any of these codes billed } \\
\text { after the decompression, they still were } \\
\text { included in our study. }\end{array}$ \\
\hline CPT-63042 & $\begin{array}{l}\text { Laminotomy (hemilaminectomy) with } \\
\text { decompression of nerve root(s) including } \\
\text { partial facetectomy foraminotomy and/or } \\
\text { excision of herniated intervertebral disc; } \\
\text { reexploration single interspace; lumbar }\end{array}$ & Included for revision cases \\
\hline
\end{tabular}


were still included in our analysis. These exclusion and inclusion criteria allowed us to isolate patients with a primary discectomy (Table 2).

We then queried the databases to determine how many patients were billed for a repeat discectomy after the index procedure. The timing of when this procedure was billed also was noted. This revision procedure was defined as the event of interest. To identify all patients who had a revision procedure, two separate survival analyses were performed. We used CPT 63042 (laminotomy, reexploration single interspace, lumbar) as the sole CPT code defining a revision procedure in our revision discectomy analysis. However, we were concerned that some patients may have had a revision procedure with codes related to lumbar arthrodesis and primary decompression, but not specifically CPT 63042. Therefore, using a broader group of revision CPT codes we performed a separate survival analysis on our cohort of patients. This group of patients was considered to have had revision surgery if they had any additional nondiscectomy lumbar surgery (Table 2). The algorithm for our database query only branches at the very end between patients who solely had a revision decompression procedure versus those who required a nondiscectomy lumbar revision procedure (Fig. 1).

For the survival analysis, we created a "life table" of surgical results. The annual revision rate was calculated from the number of revisions performed during a year divided by the number of patients with an unrevised lumbar discectomy at the start of the period of interest. Cumulative revision rates were determined from the number of patients with an unrevised lumbar discectomy divided by the total number of patients who underwent a lumbar discectomy. We used the Rothman exact method to calculate the $95 \%$ CI for each cumulative rate of survival at each time [10]. We compared the revision rate during 7 years using a $\mathrm{z}$ ratio for the significance of the difference between two ratios. A chi-square test was used to test whether the rate of revision surgery differed significantly between geographic regions. To answer whether survivorship differed based on payer type, the SAF5 and HORTHO database results were compared. We used the z-ratio for the significance of the difference between the two independent proportions (survivorship between the SAF5 and HORTHO databases) when comparing survivorship between payers. This same methodology was used when comparing data from cohorts of patients with less than 5 years of followup data and those with greater than 5 years of followup in each database.

There were a total of 7520 patients included in the HORTHO AND SAF5 databases who underwent a lumbar discectomy for an intervertebral disc displacement and had at least 5 years followup. There are substantial differences in the overall patient population of the HORTHO and SAF5 databases. For instance there are older patients in the SAF5 database and there is a higher portion of patients from the South in the HORTHO database (Table 3). However, there are still a substantial portion of patients younger than 65 years in the overall SAF5 database (14\%). These trends in age are largely continued when examining the lumbar decompression cohorts in the SAF5 and HORTHO databases (Table 4). Records for 2613 patients who had a lumbar discectomy with at least 5 years followup were included in the HORTHO database and records for 4907 patients who had a lumbar discectomy with at least 5 years followup were included in the SAF5 database.

\section{Results}

The HORTHO survivorship free from revision discectomy rate was $94 \%$ (2466 of 2613 patients; 95\% CI, 91\%-98\%). When additional nondiscectomy lumbar surgery codes were included, the survivorship free from revision surgery
Fig. 1 The breakdown of the two analyses of discectomy revision rates is shown. The patients were first selected for lumbar disc herniation, then selected for a lumbar discectomy. In the revision discectomy analysis, only patients with CPT-63042 were considered as having a revision discectomy. In the second analysis, additional nondiscectomy codes were included in the revision surgery definition.

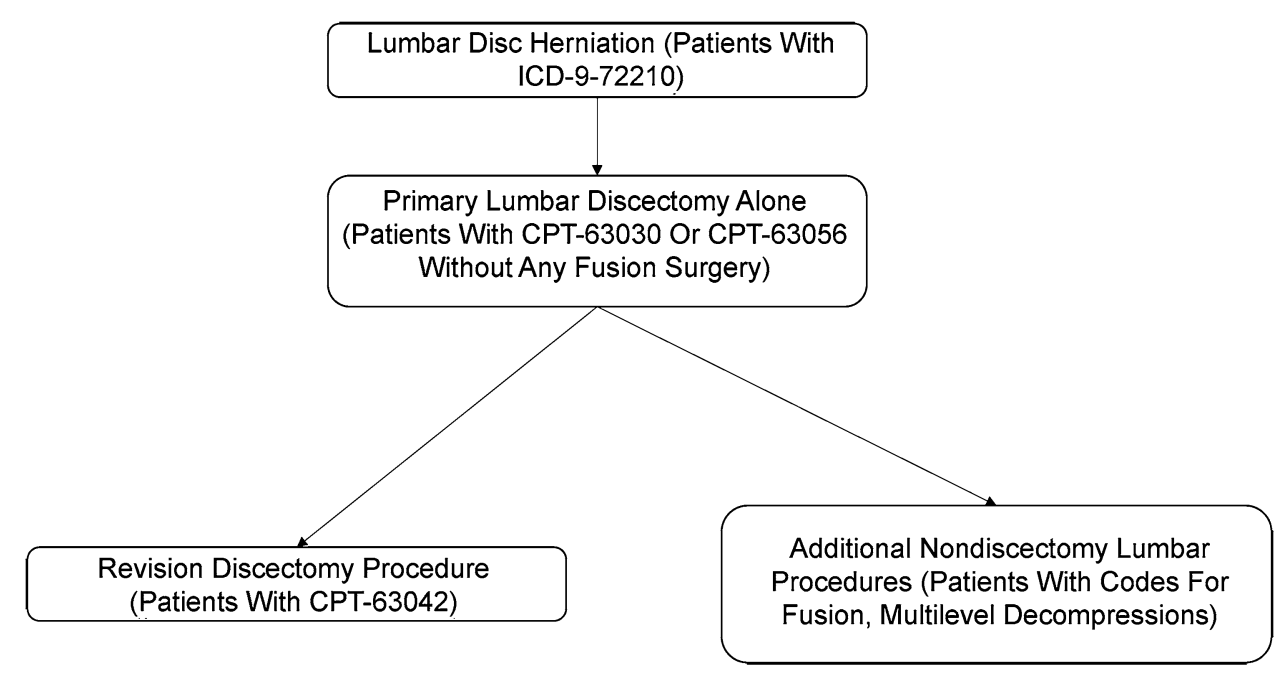


Table 3. Demographics for all patients in the Humana database and the entire Medicare patient population

\begin{tabular}{lll}
\hline $\begin{array}{l}\text { Patient } \\
\text { characteristic }\end{array}$ & $\begin{array}{l}\text { Entire HORTHO } \\
\text { databe } \\
\text { percentage } \\
\text { (number of } \\
\text { patients) }\end{array}$ & $\begin{array}{l}\text { Entire SAF5 patient population } \\
\text { percentage (number of patients) }\end{array}$ \\
\hline \multicolumn{3}{c}{ Sex } \\
Male & $44 \%(12,746,218)$ & $44 \%(24,643,570)$ \\
Female & $56 \%(9,929,851)$ & $56 \%(31,048,114)$ \\
Age distribution (years) & \\
$<30$ & $13 \%(3,038,593)$ & \\
$30-39$ & $6 \%(1,469,409)$ & \\
$40-49$ & $9 \%(1,979,621)$ & \\
$50-59$ & $12 \%(2,639,494)$ & \\
$60-64$ & $6 \%(1,358,297)$ & $14 \%(<65$ years old $)(7,813,543)$ \\
$65-69$ & $17 \%(3,963,777)$ & $18 \%(10,057,918)$ \\
$70-74$ & $14 \%(3,283,495)$ & $17 \%(9,729,337)$ \\
$75-79$ & $10 \%(2,358,311)$ & $17 \%(9,651,369)$ \\
$80+$ & $11 \%(2,585,072)$ & $33 \%(18,439,517)$ \\
Geographic region & \\
Midwest & $24 \%(5,551,102)$ & $26 \%(14,546,668)$ \\
Northeast & $8 \%(1,798,212)$ & $19 \%(10,358,653)$ \\
South & $53 \%(12,115,824)$ & $38 \%(21,385,607)$ \\
West & $14 \%(3,210,931)$ & $17 \%(9,400,756)$ \\
\hline
\end{tabular}

HORTHO = Humana orthopaedic private payer database; SAF5 = Medicare 5\% National Sample Administrative Database.

decreased to $85 \%$ (2226 of 2613 patients; 95\% CI, 82\%$89 \%)$. The SAF5 survivorship free from revision discectomy was $94 \%$ (4602 of 4907 patients; 95\% CI, 91\%97\%). When additional nondiscectomy lumbar surgery codes were included the survivorship free from revision discectomy was $83 \%$ (4085 of 4907 patients; 95\% CI, $81 \%-86 \%$ ). The life table of surgical results for the HORTHO and SAF5 databases shows high levels of survivorship at 7 years followup. There were higher survivorship rates when using a revision discectomy alone as a reoperation event (Table 5) and lower survivorship when nondiscectomy lumbar surgery codes were included as a revision procedure (Table 6).

The revision discectomy rate was higher for patients younger than 65 years $(6.87 \%$ [95\% CI, $0.73 \%-13.02 \%, 75$ of 1091 ] versus $4.73 \%$ [95\% CI, $0 \%-9.88 \%, 72$ of 1522 ], $p$ $=0.02$ ). The rate of additional nondiscectomy lumbar surgery also was higher for patients younger than 65 years (17.32\% [95\% CI, $10.80 \%-23.85 \%, 189$ of 1091$]$ versus $13.01 \%$ [95\% CI $7.62 \%-18.40 \%, 198$ of 1522 ], $\mathrm{p}=0.02$ ). A breakout survival analysis was performed to observe the rate of revision surgery for patients younger than 65 years. The annual revision rate for this cohort of patients is high at
Table 4. Demographics for the patients undergoing lumbar decompression

\begin{tabular}{lll}
\hline $\begin{array}{l}\text { Patient } \\
\text { characteristic }\end{array}$ & $\begin{array}{l}\text { HORTHO } \\
\text { Lumbar } \\
\text { decompression } \\
\text { cohort } \\
\text { percentage } \\
\text { (number of } \\
\text { patients) }\end{array}$ & $\begin{array}{l}\text { SAF5 lumbar decompression } \\
\text { cohort percentage (number of } \\
\text { patients) }\end{array}$ \\
& \\
\hline Sex & & \\
Male & $53 \%(1389)$ & $49 \%(2421)$ \\
Female & $47 \%(1224)$ & $51 \%(2486)$ \\
Age distribution (years) & \\
$<30$ & $6 \%(165)$ & \\
$30-39$ & $5 \%(142)$ & \\
$40-49$ & $12 \%(304)$ & \\
$50-59$ & $15 \%(405)$ & $21 \%(1007)$ younger than 65 years \\
$60-64$ & $7 \%(174)$ & $28 \%(1390)$ \\
$65-69$ & $23 \%(593)$ & $16 \%(699)$ \\
$70-74$ & $18 \%(477)$ & $25 \%(1216)$ \\
$75-79$ & $9 \%(236)$ & $16 \%(777)$ \\
$80+$ & $4 \%(117)$ & $11 \%(517)$ \\
Geographic region & \\
Midwest & $29 \%(756)$ & $24 \%(1179)$ \\
Northeast & $1.6 \%(41)$ & \\
South & $61 \%(1602)$ & $45 \%(2232)$ \\
West & $8 \%(214)$ & $16 \%(797)$ \\
\hline
\end{tabular}

HORTHO = Humana orthopaedic private payer database; SAF5 = Medicare 5\% National Sample Administrative Database.

Year 1 and declines during each subsequent year (Table 7). This same pattern of higher revision rates at Year 1 with subsequent drop in revision rate afterward is seen when additional nondiscectomy lumbar surgeries are included as a revision procedure (Table 8 ). The survival curves for patients younger than 65 years in the HORTHO database, the overall HORTHO database, and the SAF5 database show the same overall trend although the lowest survival rate is for patients younger than 65 years (Fig. 2). There was no difference in revision discectomy rates across geographic regions $(p=0.41)$ at greater than 7 years (Table 9). Similarly, there was no difference in additional nondiscectomy lumbar surgery rates $(p=0.68)$ across geographic regions over 7 years (Table 9). There was no difference in revision discectomy rates between patients covered by Medicare (6.22\% [95\% CI 3.33\%-9.10\%], 305 of 4907 ) versus Humana (5.63\% [95\% CI, $1.68 \%-9.57 \%$ ], 147 of 2613) $(\mathrm{p}=0.31)$.

A separate analysis was performed to analyze the cohort of patients who did not have the full 5 years followup after their initial decompression surgery. There was a significant portion of patients in the SAF5 database (7078 patients) 
Table 5. Life table for survival analysis of all patients who had a lumbar decompression

\begin{tabular}{|c|c|c|c|c|c|c|c|c|}
\hline $\begin{array}{l}\text { Time since } \\
\text { operation (Years) }\end{array}$ & $\begin{array}{l}\text { Number } \\
\text { at start }\end{array}$ & $\begin{array}{l}\text { Number } \\
\text { at risk }\end{array}$ & $\begin{array}{l}\text { Number } \\
\text { revised }\end{array}$ & $\begin{array}{l}\text { Annual revision } \\
\text { rate }(\%)\end{array}$ & $\begin{array}{l}\text { Annual survival } \\
\text { rate }(\%)\end{array}$ & $\begin{array}{l}\text { Cumulative } \\
\text { survival rate }(\%)\end{array}$ & $\begin{array}{l}95 \% \text { interval } \\
\text { LB }(\%)\end{array}$ & $\begin{array}{l}95 \% \text { interval } \\
\text { UB }(\%)\end{array}$ \\
\hline HORTHO 1 & 2613 & 2613 & 120 & 5 & 95 & 95 & 92 & 100 \\
\hline SAF5 & 4907 & 4907 & 235 & 5 & 95 & 95 & 93 & 100 \\
\hline Total & 7520 & 7520 & 355 & 5 & 95 & 95 & 93 & 100 \\
\hline HORTHO 2 & 2493 & 2493 & 61 & 2 & 98 & 93 & 89 & 97 \\
\hline SAF5 & 4672 & 4672 & 173 & 4 & 96 & 92 & 89 & 94 \\
\hline Total & 7165 & 7165 & 234 & 3 & 97 & 92 & 90 & 94 \\
\hline HORTHO 3 & 2432 & 2432 & 48 & 2 & 98 & 91 & 88 & 95 \\
\hline SAF5 & 4499 & 4499 & 120 & 2 & 97 & 89 & 86 & 92 \\
\hline Total & 6931 & 6931 & 168 & 2 & 98 & 90 & 88 & 92 \\
\hline HORTHO 4 & 2384 & 2384 & 51 & 2 & 98 & 89 & 86 & 93 \\
\hline SAF5 & 4379 & 4379 & 91 & 2 & 98 & 87 & 85 & 90 \\
\hline Total & 6763 & 6763 & 142 & 2 & 98 & 88 & 86 & 90 \\
\hline HORTHO 5 & 2333 & 2333 & 47 & 2 & 98 & 87 & 84 & 91 \\
\hline SAF5 & 4288 & 4288 & 78 & 2 & 98 & 86 & 83 & 88 \\
\hline Total & 6621 & 6621 & 125 & 2 & 98 & 86 & 84 & 89 \\
\hline HORTHO 6 & 2286 & 2286 & 42 & 2 & 98 & 86 & 82 & 90 \\
\hline SAF5 & 4210 & 4210 & 77 & 2 & 98 & 84 & 82 & 87 \\
\hline Total & 6496 & 6496 & 119 & 2 & 98 & 85 & 83 & 87 \\
\hline HORTHO 7+ & 2244 & 2244 & 18 & $0.80 *$ & $99 *$ & 85 & 82 & 89 \\
\hline SAF5 & 4133 & 4133 & 48 & $1^{*}$ & $99 *$ & 83 & 81 & 86 \\
\hline Total & 6377 & 6377 & 66 & $1^{*}$ & $99 *$ & 84 & 82 & 86 \\
\hline
\end{tabular}

HORTHO = Humana orthopaedic private payer database; SAF5 = Medicare 5\% National Sample Administrative Database; these data include patients with an additional nondiscectomy lumbar surgery (a larger group of revision CPT codes); cumulative rate of survival is $83 \%$ at 7 years; there was a lower cumulative survival rate when using an expanded definition of revision CPT code; $L B=$ lower bound; UB = upper bound; *Year 7 figures represent all revisions done after 7 years from the original surgery.

who had a primary discectomy, but did not have sufficient 5 year followup in the Medicare database (Table 10). Similarly, there was a large portion of patients in the HORTHO database who did not have 5 years followup $(18,803$ patients). In the SAF5 database, there were relatively small differences in age and region between the group lost to followup and those with 5 years of followup. There was a significantly higher rate of revision surgery for patients in the SAF5 database who had full 5-year followup data compared with patients lost to followup. There was a larger portion of younger patients in the group lost to followup in the HORTHO database. Regional differences were small between the cohort lost to followup and those with 5 years followup (Table 11).

\section{Discussion}

The previously published data regarding revision rates of discectomies involve a relatively small number of patients from a small number of institutions [9, 10]. Given that discectomy and lumbar decompression surgeries are common procedures, the rate of revision discectomies is vital to precisely define the survivorship of a primary discectomy or lumbar decompressive procedure. This is important not only to accurately calculate possible costs related to revision surgery, but also to better inform our patients regarding the risks associated with the primary surgery. We sought to determine the rate of revision discectomy on a national scale and analyze differences in revision discectomy rates based on age of the patient, region of the country, or the payer type. We were able to calculate the survivorship of a lumbar discectomy, which ranged from $91 \%$ to $94 \%$, and was higher for patients younger than 65 years when revisions were solely defined as lumbar decompression procedures. The survivorship did not vary based on payer type. The survivorship is lower, however, if the revision surgery includes any type of nondiscectomy-related surgery $(83 \%-85 \%)$.

This study has limitations as with any review of claims data. As with other large database studies that rely on physician or hospital billing of CPT, ICD-9, and diagnosisrelated codes codes, there are weaknesses related to discrepancies between claims databases and patient 
Table 6. Life table for survival analysis for all patients who had lumbar decompression

\begin{tabular}{|c|c|c|c|c|c|c|c|c|}
\hline $\begin{array}{l}\text { Time since } \\
\text { operation (years) }\end{array}$ & $\begin{array}{l}\text { Number } \\
\text { at start }\end{array}$ & $\begin{array}{l}\text { Number } \\
\text { at risk }\end{array}$ & $\begin{array}{l}\text { Number } \\
\text { revised }\end{array}$ & $\begin{array}{l}\text { Annual revision } \\
\text { rate }(\%)\end{array}$ & $\begin{array}{l}\text { Annual survival } \\
\text { rate }(\%)\end{array}$ & $\begin{array}{l}\text { Cumulative } \\
\text { survival rate }(\%)\end{array}$ & $\begin{array}{l}95 \% \text { interval } \\
\text { LB }(\%)\end{array}$ & $\begin{array}{l}95 \% \text { interval } \\
\text { UB }(\%)\end{array}$ \\
\hline HORTHO 1 & 2613 & 2613 & 72 & 3 & 97 & 97 & 94 & 100 \\
\hline SAF5 & 4907 & 4907 & 131 & 3 & 97 & 97 & 95 & 100 \\
\hline Total & 7520 & 7520 & 203 & 3 & 97 & 97 & 95 & 99 \\
\hline HORTHO 2 & 2541 & 2541 & 30 & 1 & 99 & 96 & 92 & 100 \\
\hline SAF5 & 4776 & 4776 & 60 & 1 & 99 & 96 & 93 & 99 \\
\hline Total & 7317 & 7317 & 90 & 1 & 99 & 96 & 94 & 98 \\
\hline HORTHO 3 & 2511 & 2511 & 13 & 0.52 & 99 & 96 & 92 & 99 \\
\hline SAF5 & 4716 & 4716 & 36 & 0.76 & 99 & 95 & 93 & 98 \\
\hline Total & 7227 & 7227 & 49 & 0.68 & 99 & 95 & 93 & 98 \\
\hline HORTHO 4 & 2498 & 2498 & 8 & 0.32 & 99 & 95 & 92 & 99 \\
\hline SAF5 & 4680 & 4680 & 31 & 0.66 & 99 & 95 & 92 & 98 \\
\hline Total & 7178 & 7178 & 39 & 0.54 & 99 & 95 & 93 & 97 \\
\hline HORTHO 5 & 2490 & 2490 & 13 & 0.52 & 99 & 95 & 91 & 99 \\
\hline SAF5 & 4649 & 4649 & 19 & 0.41 & 99 & 94 & 92 & 97 \\
\hline Total & 7139 & 7139 & 32 & 0.45 & 99 & 95 & 92 & 97 \\
\hline HORTHO 6 & 2477 & 2477 & 7 & 0.28 & 100 & 94 & 91 & 98 \\
\hline SAF5 & 4630 & 4630 & 12 & 0.26 & 100 & 94 & 91 & 97 \\
\hline Total & 7107 & 7107 & 19 & 0.27 & 100 & 94 & 92 & 96 \\
\hline HORTHO 7+ & 2470 & 2470 & 4 & $0.16^{*}$ & $100 *$ & 94 & 91 & 98 \\
\hline SAF5 & 4618 & 4618 & 16 & $0.35^{*}$ & $100 *$ & 94 & 91 & 97 \\
\hline Total & 7088 & 7088 & 20 & $0.28 *$ & $100 *$ & 94 & 92 & 96 \\
\hline
\end{tabular}

HORTHO = Humana orthopaedic private payer database; SAF5 = Medicare 5\% National Sample Administrative Database; these data include patients who had revision surgery only, with CPT-63042. LB = lower bound; UB = upper bound; the rate of revision goes down significantly over the years; there were high cumulative survival rates throughout the study period; *year 7 figures represent all revisions done after 7 years from the original surgery.

Table 7. Life table for survival analysis for patients younger than 65 years who had a lumbar decompression*

\begin{tabular}{|c|c|c|c|c|c|c|c|c|}
\hline $\begin{array}{l}\text { Time since } \\
\text { operation (years) }\end{array}$ & $\begin{array}{l}\text { Number } \\
\text { at start }\end{array}$ & $\begin{array}{l}\text { Number } \\
\text { at risk }\end{array}$ & $\begin{array}{l}\text { Number } \\
\text { revised }\end{array}$ & $\begin{array}{l}\text { Annual revision } \\
\text { rate }(\%)\end{array}$ & $\begin{array}{l}\text { Annual survival } \\
\text { rate }(\%)\end{array}$ & $\begin{array}{l}\text { Cumulative } \\
\text { survival rate }(\%)\end{array}$ & $\begin{array}{l}95 \% \text { interval } \\
\text { LB }(\%)\end{array}$ & $\begin{array}{l}95 \% \text { interval } \\
\text { UB }(\%)\end{array}$ \\
\hline 1 & 1091 & 1091 & 36 & 3 & 97 & 97 & 91 & 100 \\
\hline 2 & 1055 & 1055 & 16 & 2 & 98 & 95 & 90 & 100 \\
\hline 3 & 1039 & 1039 & 5 & 0.48 & 99 & 95 & 89 & 100 \\
\hline 4 & 1034 & 1034 & 5 & 0.48 & 99 & 94 & 89 & 100 \\
\hline 5 & 1029 & 1029 & 8 & 0.78 & 99 & 94 & 88 & 100 \\
\hline 6 & 1021 & 1021 & 3 & 0.29 & 99 & 93 & 88 & 100 \\
\hline $7+$ & 1018 & 1018 & 2 & 0.20 & 99 & 93 & 88 & 99 \\
\hline
\end{tabular}

*Only revision procedures coded with CPT-63042 included; LB = lower bound; UB = upper bound; the rate of revision goes down significantly over the years.

chart reviews [4]. Hospitals and providers, however, have a vested interest in accurately portraying charges for thirdparty payers to avoid fraud allegations and to be appropriately compensated for their work. In addition, given the complexities of CPT coding, we had to assume that if a patient had the ICD-9 code related to intervertebral disc disorder inserted on their chart on the day of surgery, then the lumbar decompression included a discectomy when using the specific CPT codes listed above (ie, CPT-63030 or CPT-63056). While the patient population described in this study is large, it is representative of the United States alone and may not apply to other nations or communities. It 
Table 8. Life table for survival analysis of patients younger than 65 years who had a lumbar decompression*

\begin{tabular}{|c|c|c|c|c|c|c|c|c|}
\hline $\begin{array}{l}\text { Time since } \\
\text { operation (years) }\end{array}$ & $\begin{array}{l}\text { Number } \\
\text { at start }\end{array}$ & $\begin{array}{l}\text { Number } \\
\text { at risk }\end{array}$ & $\begin{array}{l}\text { Number } \\
\text { revised }\end{array}$ & $\begin{array}{l}\text { Annual revision } \\
\text { rate }(\%)\end{array}$ & $\begin{array}{l}\text { Annual survival } \\
\text { rate }(\%)\end{array}$ & $\begin{array}{l}\text { Cumulative } \\
\text { survival rate }(\%)\end{array}$ & $\begin{array}{l}95 \% \text { interval } \\
\text { LB }(\%)\end{array}$ & $\begin{array}{l}95 \% \text { interval } \\
\text { UB }(\%)\end{array}$ \\
\hline 1 & 1091 & 1091 & 49 & 4 & 96 & 96 & 90 & 100 \\
\hline 2 & 1042 & 1042 & 29 & 3 & 97 & 93 & 87 & 99 \\
\hline 3 & 1013 & 1013 & 25 & 2 & 98 & 91 & 85 & 96 \\
\hline 4 & 988 & 988 & 27 & 3 & 97 & 88 & 83 & 94 \\
\hline 5 & 961 & 961 & 29 & 3 & 97 & 85 & 80 & 91 \\
\hline 6 & 932 & 932 & 18 & 2 & 98 & 84 & 79 & 89 \\
\hline $7+$ & 914 & 914 & 12 & 1 & 99 & 83 & 77 & 88 \\
\hline
\end{tabular}

*Includes all patients with additional nondiscectomy revision lumbar surgeries; LB = lower bound; UB = upper bound; the rate of revision goes down significantly over the years.
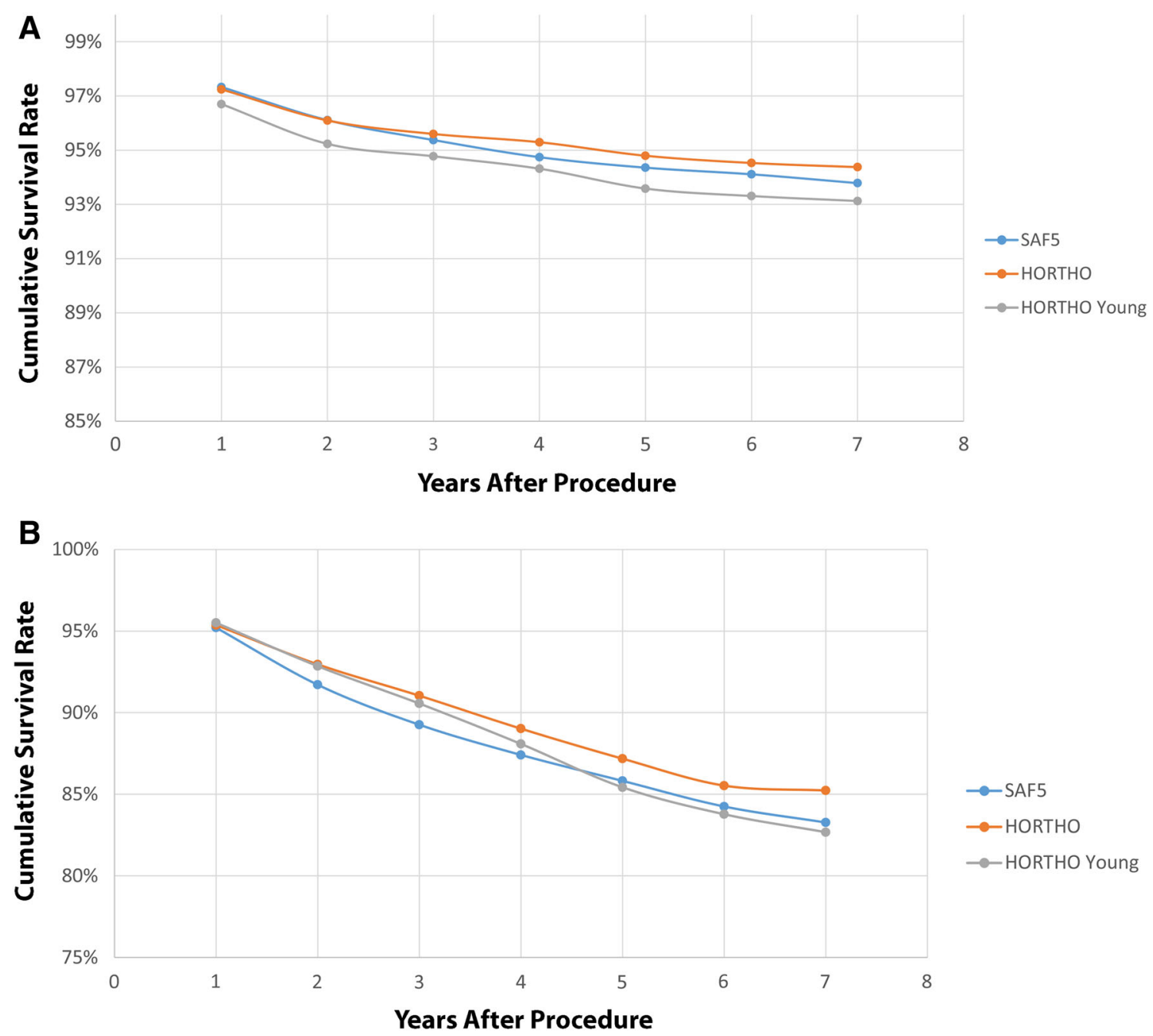

Fig. 2A-B The survival curves are shown for (A) patients younger than 65 years and combined total patient results in the HORTHO and SAF5 databases, defining failure as revision surgery coding for CPT63042. The survival rate stays greater than $90 \%$ to 7 years for all three groups. HORTHO young refers to the patients younger than 65 years.
Survival curves are shown for (B) patients younger than 65 years and combined total patient results in the HORTHO and SAF5 databases, defining failure as revision surgery that includes additional nondiscectomy lumbar surgery codes. The survival rate decreases, but never drops below $80 \%$. 
Table 9. Regional variation in survivorship rates when combining the SAF5 and HORTHO databases

\begin{tabular}{lll}
\hline Region & $\begin{array}{l}\text { Discectomy } \\
\text { survivorship (95\% } \\
\text { CI) }\end{array}$ & $\begin{array}{l}\text { Discectomy survivorship Additional } \\
\text { nondiscectomy lumbar surgeries } \\
\text { included as a revision procedure } \\
(95 \% \mathrm{CI})\end{array}$ \\
\hline Midwest & $94 \%(90 \%-99 \%)$ & $84 \%(75 \%-94 \%)$ \\
Northeast & $93 \%(86 \%-99 \%)$ & $83 \%(70 \%-99 \%)$ \\
South & $94 \%(91 \%-97 \%)$ & $84 \%(78 \%-91 \%)$ \\
West & $94 \%(88 \%-99 \%)$ & $82 \%(71 \%-95 \%)$ \\
\hline
\end{tabular}

SAF5 $=$ Medicare 5\% National Sample Administrative Database; HORTHO = Humana orthopaedic private payer database.

Table 10. Analysis of patients lost to followup in the SAF5 database

\begin{tabular}{lllc}
\hline SAF5 & $\begin{array}{l}5 \text { years } \\
\text { followup }\end{array}$ & $\begin{array}{l}\text { Lost to } \\
\text { followupp }\end{array}$ & p value \\
\hline $\begin{array}{l}\text { Total number of patients } \\
\text { Charlson Comorbidity }\end{array}$ & $\begin{array}{l}5( \pm 2.76) \\
\quad \text { Index }\end{array}$ & 6078 & \\
Age (years) & & & $<0.001$ \\
64 and younger & $21 \%(1007)$ & $22 \%(1528)$ & 0.17 \\
65-69 & $28 \%(1390)$ & $30 \%(2092)$ & 0.16 \\
$70-74$ & $25 \%(1216)$ & $21 \%(1506)$ & $<0.001$ \\
$75-79$ & $16 \%(777)$ & $15 \%(1080)$ & 0.39 \\
$80+$ & $11 \%(517)$ & $12 \%(872)$ & 0.33 \\
Region & & & \\
$\quad$ Midwest & $24.03 \%(1179)$ & $23 \%(1662)$ & 0.49 \\
Northeast & $14.25(699)$ & $14 \%(1005)$ & 0.98 \\
South & $45.48 \%(2232)$ & $45 \%(3164)$ & 0.32 \\
$\quad$ West & $16.24 \%(797)$ & $18 \%(1247)$ & 0.04 \\
Required revision & $17 \%(822)$ & $27 \%(1877)$ & $<0.001$ \\
$\quad$ surgery & & & \\
\hline
\end{tabular}

SAF5 $=$ Medicare 5\% National Sample Administrative Database.

also is possible that inherent systemic issues in coding are consistent between each database, and may not be accurately accommodated in our data analysis. Furthermore, we acknowledge that there may be some patients with symptomatic disc reherniations who never have revision surgery. Given limitations in ICD-9 and CPT coding, we are unable to accurately track these patients in the databases we used.

This study is the first, to our knowledge, to report on a national scale the precise survivorship of lumbar decompressive surgeries involving discectomy and the possible effects of payer type, geographic location, and age on the survivorship for patients. Our overall survivorship data ranged from $91 \%$ to $94 \%$ when only including lumbar discectomies, which is lower than the results reported by Gaston and Marshall [10]. This is likely because our definition of survivorship was broader. Our study does not
Table 11. Analysis of patients lost to followup in the HORTHO database

\begin{tabular}{llll}
\hline HORTHO & $\begin{array}{l}\text { 5 years } \\
\text { followup }\end{array}$ & $\begin{array}{l}\text { Lost to } \\
\text { followup }\end{array}$ & p Value \\
\hline $\begin{array}{l}\text { Total number of } \\
\text { patients }\end{array}$ & 2613 & 18,803 & \\
$\begin{array}{l}\text { Charlson Comorbidity } \\
\text { Index }\end{array}$ & $1( \pm 2.03)$ & $1( \pm 2.50)$ & $\begin{array}{c}\text { Approximately } \\
1.0\end{array}$ \\
Age (years) & & & \\
$<30$ & $6.31 \%(165)$ & $4.32 \%(813)$ & $<0.001$ \\
30-39 & $5.45 \%(142)$ & $11 \%(2135)$ & $<0.001$ \\
$40-49$ & $12 \%(304)$ & $15 \%(2854)$ & $<0.001$ \\
$50-59$ & $15 \%(405)$ & $17 \%(3278)$ & 0.13 \\
$60-64$ & $6.67 \%(174)$ & $8.93 \%$ & $<0.001$ \\
& & $(1679)$ & \\
$65-69$ & $23 \%(593)$ & $16 \%(3030)$ & $<0.001$ \\
$70-74$ & $18 \%(477)$ & $14 \%(2661)$ & $<0.001$ \\
$75-79$ & $9.04 \%(236)$ & $7.45 \%$ & $<0.001$ \\
& & $(1400)$ & \\
$80+$ & $4.48 \%(117)$ & $5.09 \%(975)$ & 0.07 \\
Region & & & \\
Midwest & $29 \%(756)$ & $27 \%(5059)$ & 0.03 \\
Northeast & $1.57 \%(41)$ & $1.71 \%(322)$ & 0.6 \\
South & $61 \%(1602)$ & $63 \%(11831)$ & 0.11 \\
West & $8.19 \%(214)$ & $8.46 \%(1591$ & 0.64 \\
Required revision & $15 \%(387)$ & $12 \%(2199)$ & $<0.001$ \\
surgery & & & \\
\hline
\end{tabular}

HORTHO = Humana orthopaedic private payer database.

differentiate whether reoperations are the result of ongoing unresolved symptoms or are reflective of a symptom-free period with a recurrent herniation. We believe this is a more-accurate definition of survivorship as it reflects whether a surgery was successful in relieving the neurologic symptoms from a disc herniation. A small study found that eight of 41 patients who underwent revision microdiscectomy had revision for a reason other than recurrent disc herniation at the level of the primary disc herniation [18]. These patients (20\% of the study cohort) might not have been included as having a revision procedure in previous studies. Inclusion of this cohort of patients who had revision surgery, as was done in our study, creates a more-accurate picture of survivorship for a lumbar discectomy.

Our results show a high rate of dropout from the SAF5 and HORTHO databases. This is a significant limitation as we do not have complete information regarding why this cohort of patients left either the Medicare or Humana databases. Our analysis did show that younger patients were more likely to leave the private payer Humana database. Given the changing American economy during the years of the study (2005-2014) and the laws governing 
healthcare administration, there may be myriad reasons why young people left a private health insurance plan. An analysis of this dropout rate is largely outside the context of our study. Furthermore, it is curious that the rate of revision surgery for the SAF5 database was higher for those staying in Medicare for $5+$ years while the rate of revision surgery for the HORTHO database was higher for those leaving Humana health insurance within 5 years of the index procedure. The higher rate of revision spinal surgery for patients who dropped out of the private health insurance may be related to inability to afford health insurance from increased disability attributable to failed back surgery. This theory, however, is difficult to prove in the context of the current study. Further research is required regarding the dropout rate from both databases.

Persistent or recurrent symptoms after discectomy are associated with substantial utilization of healthcare resources. Ambrossi et al. [1] reported that revision surgery after discectomy was associated with an average cost of USD 39,836 per patient. With greater than 5\% of patients undergoing a repeat surgery after discectomy, these direct costs are not insubstantial and indirect costs related to loss of productivity are likely to be large $[8,12]$. Clearly, a substantial amount of resources is required for treatment of patients with recurrent disc herniations and strategies tailored to reduce the rate of revision discectomy could prove to be cost-effective.

When comparisons were made between patients 65 years and older versus those younger than 65 years, higher rates of revision surgery were found for younger patients. As with other surgical procedures, patients who are younger are likely more active and may be prone to recurrent symptoms after primary surgery [7, 15]. However, differences in revision surgery rate between patients 65 years and older versus those younger than 65 years were never more than $4.5 \%$. Even though there may be a slightly higher rate of revision surgery for younger patients, they will still likely see improvements in clinical outcomes from operative treatment $[10,11,16,20,22,24]$. We did not find any regional difference in survivorship of the discectomy. To our knowledge, this is the first report on regional variation in survivorship of lumbar discectomies. The lack of regional variation is likely attributable to the relatively objective indications for a revision procedure such as amount of disability, advanced imaging, and pain. Furthermore, these relatively objective indications for revision discectomies may explain why there was not any significant difference in survivorship between Medicare and Humana patients.

Our study shows high rates of cumulative survival at 5 to 7 years after an index lumbar discectomy. Survivorship for patients undergoing a lumbar discectomy was approximately $94 \%$ during 5 to 7 years in the HORTHO and
SAF5 databases. The survivorship decreases substantially when a more broad definition of revision surgery including nondiscectomy procedures is used. Payer type and geographic region did not show a significant effect on survivorship for the lumbar discectomy procedure. We hope this information will help clinicians counsel patients on the precise risk of revision surgery after a primary lumbar discectomy. Furthermore, given the difference in revision rate when nondiscectomy-related procedures are included as revision surgeries it is important that clinicians explain that further degeneration of the lumbar spine may require larger surgeries after a primary discectomy. Future research is required to precisely define what constitutes a revision surgery after a lumbar discectomy. For instance, degeneration of an adjacent disc space requiring another discectomy and/or arthrodesis may not necessarily be related to the primary lumbar discectomy, but rather the natural course of lumbar degeneration. The effect of incorporating this revision surgery risk in the preoperative consultation will be an important avenue of investigation. These findings may be beneficial in creating realistic expectations for patients with a lumbar disc herniation. We hope these findings also may assist public policymakers and insurers when deciding how resources are allocated to patients during numerous years after a disc herniation given this known risk of revision surgery. This will be vital as accountable care organizations determine how people are treated during a number of years with various spinerelated diagnoses.

\section{References}

1. Ambrossi GL, McGirt MJ, Sciubba DM, Witham TF, Wolinsky JP, Gokaslan ZL, Long DM. Recurrent lumbar disc herniation after single-level lumbar discectomy: incidence and health care cost analysis. Neurosurgery. 2009;65:574-578; discussion 578.

2. Barth M, Diepers M, Weiss C, Thomé C. Two-year outcome after lumbar microdiscectomy versus microscopic sequestrectomy: part 2: radiographic evaluation and correlation with clinical outcome. Spine (Phila Pa 1976). 2008;33:273-279.

3. Barth M, Weiss C, Thome C. Two-year outcome after lumbar microdiscectomy versus microscopic sequestrectomy: part 1: evaluation of clinical outcome. Spine (Phila Pa 1976). 2008;33:265-272.

4. Bozic KJ, Chiu VW, Takemoto SK, Greenbaum JN, Smith TM, Jerabek SA, Berry DJ. The validity of using administrative claims data in total joint arthroplasty outcomes research. $J$ Arthroplasty. 2010;25:58-61.

5. Centers for Medicare and Medicaid Services. 2003 CMS Statistics. Available at: https://www.cms.gov/Research-Statistics-Dataand-Systems/Statistics-Trends-and-Reports/CMS-Statistics-Refer ence-Booklet/Downloads/2003CMSStatistics.pdf. Accessed July 18, 2017.

6. Dewing CB, Provencher MT, Riffenburgh RH, Kerr S, Manos RE. The outcomes of lumbar microdiscectomy in a young, active population: correlation by herniation type and level. Spine (Phila Pa 1976). 2008;33:33-38. 
7. Dy CJ, Bozic KJ, Padgett DE, Pan TJ, Marx RG, Lyman S. Is changing hospitals for revision total joint arthroplasty associated with more complications? Clin Orthop Relat Res. 2014;472:2006-2015.

8. Ekman M, Jonhagen S, Hunsche E, Jonsson L. Burden of illness of chronic low back pain in Sweden: a cross-sectional, retrospective study in primary care setting. Spine (Phila Pa 1976). 2005;30:1777-1785.

9. Findlay GF, Hall BI, Musa BS, Oliveira MD, Fear SC. A 10-year follow-up of the outcome of lumbar microdiscectomy. Spine (Phila Pa 1976). 1998;23:1168-1171.

10. Gaston P, Marshall RW. Survival analysis is a better estimate of recurrent disc herniation. J Bone Joint Surg Br. 2003;85:535537.

11. Gibson JN, Grant IC, Waddell G. The Cochrane review of surgery for lumbar disc prolapse and degenerative lumbar spondylosis. Spine (Phila Pa 1976). 1999;24:1820-1832.

12. Horng YS, Hwang YH, Wu HC, Liang HW, MHE YJ, Twu FC, Wang JD. Predicting health-related quality of life in patients with low back pain. Spine (Phila Pa 1976). 2005;30:551-555.

13. Kelly MP, Savage JW, Bentzen SM, Hsu WK, Ellison SA, Anderson PA. Cancer risk from bone morphogenetic protein exposure in spinal arthrodesis. $J$ Bone Joint Surg Am. 2014;96:1417-1422.

14. Montgomery SR, Ngo SS, Hobson T, Nguyen S, Alluri R, Wang JC, Hame SL. Trends and demographics in hip arthroscopy in the United States. Arthroscopy. 2013;29:661-665.

15. Padegimas EM, Maltenfort M, Lazarus MD, Ramsey ML, Williams GR, Namdari S. Future patient demand for shoulder arthroplasty by younger patients: national projections. Clin Orthop Relat Res. 2015;473:1860-1867.
16. Pappas CT, Harrington T, Sonntag VK. Outcome analysis in 654 surgically treated lumbar disc herniations. Neurosurgery. 1992;30:862-866.

17. Patel AA, Singh K, Nunley RM, Minhas SV. Administrative databases in orthopaedic research: pearls and pitfalls of big data. J Am Acad Orthop Surg. 2016;24:172-179.

18. Patel N, Pople IK, Cummins BH. Revisional lumbar microdiscectomy: an analysis of operative findings and clinical outcome. Br J Neurosurg. 1995;9:733-738.

19. PearlDiver Inc. Healthcare Research - Research Capabilities. Available at: http://pearldiverinc.com/researchinfo.html. Accessed June 25, 2017.

20. Pearson AM, Blood EA, Frymoyer JW, Herkowitz H, Abdu WA, Woodward R, Longley M, Emery SE, Lurie JD, Tosteson TD. SPORT lumbar intervertebral disk herniation and back pain: does treatment, location, or morphology matter? Spine (Phila Pa 1976). 2008;33:428-435.

21. Puvanesarajah V, Jain A, Cancienne JM, Shimer AL, Singla A, Shen F, Hassanzadeh $\mathrm{H}$. Complication and reoperation rates following surgical management of cervical spondylotic myelopathy in MedicarebBeneficiaries. Spine (Phila Pa 1976). 2017;42:1-7.

22. Radcliff K, Cook C. Surgical treatment for lumbar disc herniation: open discectomy (indications, technique, outcomes, and complications). Sem Spine Surg. 2016;28:14-19.

23. Weinstein JN, Lurie JD, Olson P, Bronner KK, Fisher ES, Morgan TS. United States trends and regional variations in lumbar spine surgery: 1992-2003. Spine. 2006;31:2707-2714.

24. Williams RW. Microlumbar discectomy: a conservative surgical approach to the virgin herniated lumbar disc. Spine (Phila $\mathrm{Pa}$ 1976). 1978;3:175-182. 